\title{
Representing Information Need with Semantic Relations*
}

\author{
Anils. ('/akmavithy \\ MI'T' Media Labotatory
}

\begin{abstract}
Information retrieval systens can be mate luore offective by providing note expressive guery languages for users to specify their information aeed. 'This paper arganes that this can be achieved through the lase of semantic relations as query primitives, and describes a new technicue for extracling semantic relations from an online dictionary. In contrast to existing research, this technique involves the composition of basic se mantic relations, a process akin to constrained spreading activation in semantic networks. 'lthe proposed technique is evaluated in the context of extracting semantic relations that are relevant for retrieval from a corpus of pictures.
\end{abstract}

\section{Introduction}

In recent years, there has been considerable interest in applying techniques from computational linguistics to improve various aspectis of information retrieval (lik) [1]. 'This paper describes new technicules for ex tracting semantic knowledge from online lingutstic re sontes in order to provide betiter methods of express ing lli gueries.

Bolkin and Croft [2] used the term information need to characterize the user's molivation for using an IR? system. In current Ili systents, users first transiatie their information need into querios. 'The IR system processes these queries and matches them against surrogates representing the text (or media) colloctions to retrieve dementis of the collection that are possibly the best matches to the user's queries.

In most information retricval systems in wick lase the surrogates for the collection are words or word collocations that are cither extracted antomatically or provided by a human indexer. This comstrains users to express their queries ats combinations of words or word collocations, resulting in an inacenate or inadeculate description of their information need. Simcation [L] characterizes the ideal as a conceptral information

\footnotetext{
*'llhis rescarch was supported in part try a fellowship from the

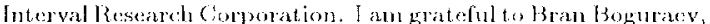
Ken Hatse, lonis Weitznan and the Machino Understanding group at the Media lable fer their fredbark on this work, An-

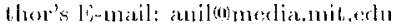

retrieval systen, wherein users express their noed as some combination of concepts and the system matehes these to concepts representing the inderlying text or media collection. Attempts have been made to build such systents for specific domains, but how to atutematically extract and reppesent concepts in general is still far from clear.

Many rescarchers in computational linguistics have recognized that electronic dictionaries could be nsed to address this conceptual information bottitencek (e.g., $[3,1]$ ) and a lol of work has been devoted lately to extracting semantic relations between words (e.g., [5]). 'This research allows queries to be ex. pressed as combinations not only of words but also of semantic rolations. 'l'o take a simple cxample, let. us assume that the system has access to a database of pictures of animals with the nanes of animals as the surrogates. If a user is interested in pictures of dogs, the query [X $\Lambda$-KINI)-(J) dog] is construeted. 'The system processes the query to retrieve pictures whosice surrogates are words like "basset houml," "beagle," and so on since the query mateles the semantic relations, [bassot hound A-KIND..Ol' dog], [beagle A-KINI) OF' (log], etce. 'Thus, semantic relations colable the user lo construct queries that correspond to entire classes of word-based queries.

the main purpesse of this paper is to describe new techniques for extracting semantic relations that were inspired by the work of Quillian [6]. Quillian demonstrated that by organizing individual semantic relations into semantic networks, one could obtain compositions of existing scmantic relations by a process of spreading activation. For example, the two relations, [basset hound $\Lambda$-KIND-(O) doge] and [dog IIAS-PART tail], can be composed to yicld [basset hound IIAS-l'AR'l bail].

In this paper, we describe a progran in which individual somantic relations extracted from a dictionary are composed to yield new semantic relations for re. trieval over a dalabase of pictures. Wo address hilree issues that arise in this connection:

- Coutrol of spreading activation: Vnbounded spreading activation often resultis in connecting words through relations that: do not fall into any desired lype. 'To bo useful, it is necessary to con-. trol spreading activation so that only relations of 
the desired types are found.

- Equivalence of alternative compositions: Depending on the configuration of the scmantic network, there might be several accoptable altematives that yield the same new composed relation.

- Word-sense ambiguity: Since individual semantic relations are extracted from the dictionary text, it is necessary to constrain the spreading activation to the "correct" senses of the target word.

Section 2 describes the test database that we have been using and semantic relations that are useful for retricval over this database. In Section 3, we describe a pattern-based approach that we have enployed to control spreading activation and recognize alternative compositions. In Section 4, we present the results and analysis of a series of testis that we conducted to test the accuracy of the program and its coverage as compared to a hand-constructed system, WordNet [7]. This section also describes and cvaluates a new word-sense disambiguation technique that is based on knowledge of the semantic relations involving the ambiguous word. Finally, Section 5 inchudes a brief summary of the work and discusses issues that need to be addressed in future work.

\section{A Database of Pictures}

The primary motivation for our work was to provide retrieval based on semantic relations for a corpus of pictures collected from the American Heritage Dictionary. The corpus contains 1359 pictures, each of which is annotated with a single word or word collocation from the dictionary. Clearly, there are a great many senantic relations that could be useful for retrieval from such a database. 'To narrow down the set of interesting semantic relations, we used the fact that the annotations are single words or word collocations. As in menory experiments in cognitive psychology, we used the annotations as cues for frce recall by association. We then analyzed the results to locate semantic relations that occurred most often. Based on this analysis, we picked the seven relations shown in Table 1 (which we will henceforth call modes to distinguish them from individual semantic relations).

The OCCURS-WITH mode refers to typical physical collocation of objects. It is useful for making "intelligent" guesses about what else might be in the picture besides the objects explicitly annotated. As the example in rable 1 shows, this is not always symmetric. It can be argued that the presence of an ax in a picture much more often indicates the presence of wood than the other way around. 'L'he PLAYS-ROLF-OF mode differs from the EXAMPLIOF mode in having a connotation of typical use. The CHARACTERISTIC-ACITIVITY mode is used to relate both objects and agents to typical activities they

\begin{tabular}{|c|c|}
\hline Mode & Examplo \\
\hline OCULS-WITH & $(a x$, wood $)$ \\
\hline EXAMPI.E & (basset hound, dog \\
\hline PLAYS-ROLF-OF & (cat, pet) \\
\hline CHĀR $\Lambda C$ TERISTIC:- & (ax, chopping) \\
\hline ACIIVITY & \\
\hline I $\triangle \mathrm{S}-\mathrm{PURPOST}$ & (aqueduct, water) \\
\hline CONGIYTUENT-OF & (balance beam, \\
\hline & gymnastics) \\
\hline HAS-CONSTITUENT & $(\log , \operatorname{leg})$ \\
\hline
\end{tabular}

'lable: 1: Modes used for picture database retrieval

are involved in. The II AS-PURPOSE mode is used to relate an object to a word denoting its purpose. As in the Table 1 exanple, that word conld either denote an activity or another object where there is a typical activity involving both objects. (OONST'T'UENT-Ol' and MAS-CONS'TIUUE'T are similar to the widelyused PAR'T-OF and II SS-PAR'I primitives except. that metaphorical inclusion is valid as well. 'The next section describes our scheme for extracting these modal relations from the dictionaryl.

\section{Extracting Modal Relations from Dictionary Definitions}

Extracting modal relations from dictionary definitions involves three components: a preprocessor that tags the definition with part-of-speech information, a module that pulls out triples (basic semantic relations of the form [wordl IINK-TYPl' word2] from the preprocessed definition, and a pattern interpreter that checks the list of triples for modal relations using sets of patterns. We will now describe each of these in turn.

for preprocessing the dictionary definitions, wo have experinented with two different taggers: the Xorox PARC, part-ol-spech tagger [8], and the (hopper [9], an optimizing finite state machine-based tagger built at the MI'I Media I,ab by Ken Ilaase. Before lagging the definition, we apply a few simple lilters to remove botanical names, usage guidelines, ete. 'The performance of both taggers was satisfactorily high. The example below shows the output of the Xerox tagger on a sample definition ${ }^{2}$ :

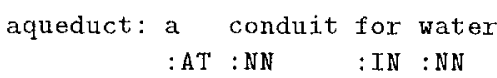

\footnotetext{
${ }^{1}$ All these experiments have been rum on a Websters online dictionary. The program is written in Lutid Common Jisp and runs on a bFCstation.

${ }^{2}$ 'The tags used are from the Brown corpus, c.g., : $\mathrm{N}^{\mathrm{T}}=\mathrm{ar}-$ ticle; $: N N=$ singular noun; $: I N=$ preposition.
} 
1. Vse library of A-KINI)-() or lin'LALS extrac tion patterns to locate the gentus term. fixtract. triples from modiliers of the genus term.

2. Iterate over the diferendiane constructing triples using each of them until cither the end of the definition or till no triple can be eonstructed from the diflerentia foumd.

3. Apply posteprocessing thethods to construct other triples usiug matching robles.

ligure 1: Procedure for extracting triples from a pre processicel definition

\subsection{Fxtracting Triples}

The algorithm for extracting triptes is built on the atssumption that dictionary defintions typically consist of a genus term (identifying its kind) followed by dif ferentian (low it is dillerent, from the gemus) [10]. In the acpeduct defintion above, the groms term is "com-

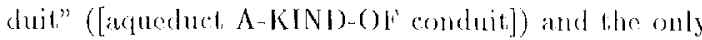
differentia is given by the P'P" "for water". In the case? of verb definitions, whe genus term is related by the link "liN'AALS". The three stages of the algorithrn are presented in figure 1.

We use a variety of patherms described in the literature to extract the initial gembs term(s) correctly [5] (o.g., patterns like "a NP," "cither of two plumal-NP,"

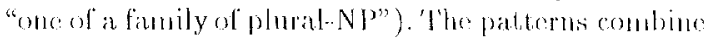
both syntactic and string elements, which nakes them nore powerful than purely string-based patterns [11]. Sine it is very importint io lind the genus term cor rectly, "Matstetitet" extractor is invoked if none of the standard patterus work. This lasteditch extractor ansumes that the tagger must have made a mistaks? and tries to compensate for common tagger mistakes (e.g., lagging an ing-form as verb instend of adjective). Once the genus terms have been found, we inalyos the morphological form of the modiliess lor triples. for instance, since "violin" in defined as "a bowed in.

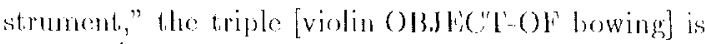
recorded"

In Step 2, each of the differentian is assuned to be cither a relative clause or a prepositional phrase. As in Step 1, head nouns or verbs are located for ach of the diflerentiace and resilt in triples being formed with the word(s) being modified. Where there is attachnent andiguty (as with prepositional platres [1:3]). triples are formed for all possible atiachorentsi.

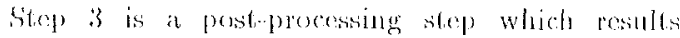
in new triples being formed and sone triples lron

"The program only hadedtes nom and verd definitions.

${ }^{4}$ ln all, there are aloud is link types in triples, namely,

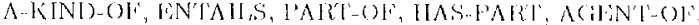

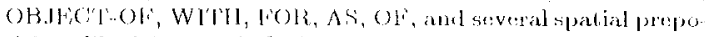
sitions like IN and ON [12].
Siep 2 being aliminated. For instance, consider the following defintition of "acropolis": "acropo lis: the upper, fortified part of a Greek city (as Athens)." In Step 3, t.wo triples produced in Sticp 2, [acropolis A-KIND-OF' part] and [part OF city] are merged into [acropolis P'AR'J-OF eity]. Similarly, there are rules for crealing links of other types. Other pest-processing, mules cleal with eliminating references to A KINI OF genus terms in triples by replacing them with the definiendum.

\subsection{Ixtracting Modal Relations from Triples}

for each modal relation in 'lable 1 , there is a set of patterns that specifies how the modal relation can he detected from the triples of one or more definitions. Wach pattem encocles a heuristic rule that is based on the triples extracted from the dietionary dedinitions. For example, one paltem for extracl ing OCOURS. WI'Tll relations encodes the heurisitic that typically if Object I and Oljecti2 are involved in

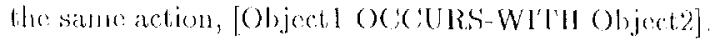
Whon this pattern is applied to the definition, "ax: a conting bool that consists of a heavy edged head fixed to a handle with the odge paralled to the landle and that is used copectally for folling trees and chopping and spliting wood", the two modal relations [ax Ocouks Wroll tree] and [ax OcCUles Wl'tll woot] are found, Pat... terms can apply to moltiple definitions as well. Using the sanne treuristice as above, we have dofined a pattem that extracts the modal relation [atomizer occolde-Wl'tle spray] from the two def. initions below:

atomizer: an instrument, for atomizing n:it ally a perfinne, disinfectant, or unedicanent atomize: to reduce to minute particles or to a. fine spriay

\section{Performance Evaluation}

To analyze the performance of the program, we picked the lirst 300 annotations from the corpus of pictures described in Soction 2. The lirst part of this section presents the results of applying the modal relittion patterns that work on one definition. 'lhe second part discusses diflicultios involved in the evaluation of modal redation patterns that work on more than one decirsition.

In order to obtain an independent estimate of the peremente of the extraction progrant ${ }^{5}$, we compared the ontput of the program where pose sible to the ontput of WordNet [7], which is a large, mantally-coded somantic network. Worel. Not does not have links corresponding to four Si.e, independent of the dietionary we are using, 


\begin{tabular}{|r|r|r|r|r|r|r|}
\hline ext & cor & $\%$ & wnt & wnII & $\%$ & $\# \mathbf{~}$ \\
\hline 471 & 321 & 68.15 & & & & 8 \\
\hline 870 & 742 & 85.28 & 537 & 138 & 25.69 & 4 \\
\hline 12 & 9 & 75.00 & & & & 2 \\
\hline 212 & 129 & 60.84 & & & & 6 \\
\hline 146 & 114 & 78.08 & & & & 6 \\
\hline 114 & 75 & 65.78 & 99 & 5 & 0.05 & 2 \\
\hline 126 & 83 & 65.87 & 124 & 4 & 0.03 & 4 \\
\hline
\end{tabular}

Table 2: Performance of the modal relation extraction progran

of the modes listed in Table 1: Occurs. WITH, PLAYS-ROLP-OL, HAS-PURPOSE, and CIIARACIERISIIC-AC'IIVITY. For the other three modes, we found correspondences by assuming that all hypenyms are valid examples of $E X \Lambda M P J E-$ OF, all meronyms of IIAS-CONSTITUISN' and all holonyms of CONSTITULN'T-OF'. The performance results and the comparison with WordNet are presented in Table 2.

The seven rows of 'Table 2 correspond to the seven modal relations of Table 1. The first column shows the total number of modal relations extracted for a mode while the sccond column gives the number of modal relations judged to be correct (by the author) with the percentage figure shown in the third column. 'The fourth column gives the number of such relations found in Word Net, while the lifth gives the number of those relations that were also found by the extraction program (with the column after that providing the percentage figure). The last column shows the uumber of modal extraction patterns implemented for the mode.

We will now briefly discuss the performatuce of the program. A detailed malysis is presented in [15]. The? precision of the extraction is over $60 \%$ in all cases; there are three main reasons for the precision not being higher:

- Many of the patierns (e.g., for OCOURS-WITlI or CHARAC'TLRISTICA ('IVITY) implicitly assume that verbs denote activity. 'This is not, true of many verbs like "suggest", "represent", "rescmble", cte.

- Many patterns hinge on the presence of particular links (like "WI'l'H" and "IN"), and precision is dragged down by their ambiguity.

- The tagger makes mistakes during the preprocessing resulting in incorrect matches for the patterns.

The number of matches with WordNet was generally low because WordNet uses word collocations as link destinations to construct more detailed hicrarchies. So, for instance, while WordNet has the link [accordion HYPERNYM free-reed instrument], our program genomates [accordion EXAMPLE-OF instruinenti].

We have not similarly analyzed the performance of patiterns that operate over two definitions. 'The main reason is that to get an accurate estimate of the precision (as in the socond column of 'Table 2), we have to combine the dictionary definition of the test word with every other definition in the dictionary. This work is in progress. However, it is clear that word-sense arribiguity can lead to poor performance by rumning modal extraction patterns over unintended senses of a word. For instance, if we return to the "atomizer" example at the end of the previous section, we find that wo are "spreading activation" through the verb "atomize." There is another sense of "atomize", viz., "to sulbject to atom bombing." which is not of interest here and should be ignored. Wo will now brielly describe a new word-sense disambiguation technique that is applicable in this context. A detailed discussion can bo found in [15].

Krovetz and Croft [14] characterized the process of word-sense disambiguation as bringing to bear sevcral kinds of evidence depending on the context of occurrence of the word, namely, part-of-speech, mor phology, subcategorization, semantic restrictions and subject classifications. Continuing in the same framework, wo decided to use the semantic relations involving an imbiguous word as another source of evidence. Let the ambiguous word be denoted by $W_{a m b}$, and $\left[W_{s m}\right.$ RELAT'ION $\left.W_{a m b}\right]$ be a triple in the lirst definition of the modal relation patiern. 'Then, each definition of $W_{\text {anub }}$ which includes the triple [ $W_{a m b}$ RLILATION-INVERSE $\left.W_{s+e}\right]$ can be considered as a correct sense (for spreading activation), where RELATION-INVERSE is the inverse link type of RLLATION ${ }^{6}$. For the same 300 words as in Thable 2 wo tested this hypothesis on three kincls of links:

1. A-KIND-OP: The inverse of A-KIND-OR is AS 'The definitions of "building" and "structure" given below illustrate the inverse relationship

building: a usually roofed and walled structure built for permanent use (as for a (welling)

structuro: something (as a buikling)

that is constructed

2. P'NR'I'OF', whose inverse is IIAS-P'AR'T'

3. IIAS-PART, whose inverse is PART-Ol'

The results were very disappointing, with less than $5 \%$ of the words tested being successfully disam. biguated by this technique. Often the problem seemed that the inverso link was present, but using a synonym or a hyponym. To test this, we conducted an experiment on HAS PAR'l' where all we required to judge a

\footnotetext{
${ }^{6}$ (hearly, this technique only applies to dictionaries and other text sources which are definitional in nature.
} 
definition as correct was the presence of some PAR'lOf' triple, no matter what it was part of. 'This made the technique too general and ineflective. Out of the 103 H AS-PART' relations tested, there were 14 corret disambigualion cases and 35 incorrect cases.

$A$ more eflective techmiane seems to bo to use the modifiess of the anbiguons word. We conducted an experiment on A-KINJ)-(OF links in which, for an ambiguous deliniendum, we accepted as the correct senses those defintions whose genus terms had somo modifiers in common with the definiendum in its orig. inal context. Out of the 860 entries tested, there were 84 correct disambiguations and 39 incorect ones.

\section{Conclusions}

'This paper is based on the argunent that semantic relations can provide a better way for users to express their information need to an IIR system. For such an interface to be widely applicable, the IR system shonld be capable of automatically accuiring semantic rela tions from available linguistic resourees rathes than through hand coding. Recent, work in semantic knowledge extraction from online dictionaries seems like a promising nothod of antomatic ancentisition. 'This paper describes a new tochuique for extraction from dictionaries that was inspired by the woll-known mechanism of spreading activation in semantic networks. 'The teechnique rolies on sets of patterns to compose basic semantic relations from one or more dictionary definitions into modal relations between words. Wo evaluate this technique in the context of seven modes that are useful for retricval from a catabase of pictures. linally, we propose and evaluale a new tech. nique for word-sense disambignation within dictionary definitions that makes use of semantice relations involv ing the ambiguous word.

Wo plan to extend this work in many directions. Wo would like to develop a stamdard grammar for defining modal relation palterns, and an intepereter for this standard grammar. Once the grammar is available, we inteud to develop an interface for specifying new modal relations and palderns for detecting them over multiple delinitions. Wo also plan to inconporate im plementations of existing word-sense disambiguntion algorithus into the modal pattern interpeter. From an IR perspective, wo plan to investigate the synergislice use of modal relations with other query primitives like keywords for petricual from an extemded database of annotated pictures. One desiralyle result of this work for future research would be the establishment of standard benchmarks and test suites for retricval from picture databases.

\section{References}

[1] Sncaton, A. L". "Progress in the Application of Natural language Processing to Information Re tricval 'lasks," in Comp. Jnl, 35(3), 1992.

[2] Belkin, N. J., and Croft, W. B. "Information l'iltoring and Information Retrieval: 'Two Sides of the Same Coin?," in CACM, 35(12), 1992.

[:3] Lox, li. A., Nutter, .t. T', Ahlswede, 'I., livens, M., and Markowitz, J. "Building a large Thesilurus for Information Retricval," in Proce of the Second Conferense on Applied Nhl', 1988.

[4] Wilks, Y., Fass, J), (iuo, (., Mclonald, I., Plate. A., and Slator, B, "Providing Machine 'Tructable Dictionary 'Tools," in Semantics and the hexicon, J. I'ustejorsky, oditor, Kluwer Academic Publishers, 1993.

[5] Chodorow, M.S., Byrd, R. J., and fleidorn, G. L) "lixtracting Somantic Hierarchies from a Large On-Linc I)ictionary," in Proce of $A(2,-3,1985$.

[6] Quillian, M .R. "Semantic Menory," in Semantic Information Processing, M. I. Minsky, ed., MII press, 1968.

[7] Miller, (․ A., and l'ellbanm, (․ "Semantice Networks of linglish," in Cognition, 41, 1991.

[8] Cutting, D., Kupiec, J., Pedersen, J. and Sibun, P. "A P'ractical Part.of-Speech 'Tagger," in Proe. of the 3rd Conf. on Applied NLP, 1992.

[9] Haass, K. 13. "Multi-Scale Parsing using Optimizing linite-Stalle Machines," Internal Memo, Ml'l" Media Laboratory, 1993.

[10] Anster, R. "lhe Structure of the Mertian Wobster Pocked Diclionary," Pho Dissertaliom, Whiversity of T'exas, Austin, 1980.

[11] Montemagni, S. and Vanderwende, L. "Structural Patiterns vs. String l'atterns for lextract. ing Semantic Information from Dictionaries" in

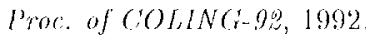

[12] Miller, G. A., and Jolnson-Laird, P'. N. Language and P'erecplion, Harvard U. Press, 1976.

[13] Jensen, K., and Binot, J-L. "I)isambiguading Prepositional Phase Attachuents by Using (OnLine Dictionary Delinitions," in Compulational Linguistics, 13, 3-4, pl 251-260, 1588.

[11] Krovetz, R., and (Gol't, W. I3. "Word Sense J)is anbignation Using Machine-Readable Dictionatiss," in Proce of Sicilh-89, 1989.

[15] Chakravarthy, $\Lambda$. S. "Representing lnformation Ned with Semantic Relations," Internal Memo, MI'l Media Laboratory, 1993. 